\title{
Prognostic value of pigment epithelium-derived factor for neoadjuvant radiation therapy in patients with locally advanced rectal carcinoma
}

\author{
HAIZHAO YI $^{1 *}$, DENGBO JI ${ }^{1 *}$, TIANCHENG ZHAN ${ }^{1}$, YUNFENG YAO ${ }^{1}$, \\ MING LI ${ }^{1}$, JINYING JIA ${ }^{1}$, ZHAOWEI LI ${ }^{1}$ and $\mathrm{JIN} \mathrm{GU}^{1,2}$ \\ ${ }^{1}$ Key Laboratory of Carcinogenesis and Translational Research (Ministry of Education), \\ Department of Gastrointestinal Surgery III, Peking University Cancer Hospital and Institute, Haidian, \\ Beijing 100142; ${ }^{2}$ Peking-Tsinghua Center for Life Sciences, Tsinghua University, Beijing 100084, P.R. China
}

Received March 31, 2016; Accepted May 25, 2016

DOI: $10.3892 /$ ijo.2016.3620

\begin{abstract}
The aim of the study was to investigate the prognostic value of pigment epithelium-derived factor (PEDF) in locally advanced rectal carcinoma (LARC) treated with neoadjuvant radiation therapy (nRT). The level of PEDF expressing was examined in LARC tissues treated with nRT by immunohistochemistry and the prognostic significance of PEDF was analysed by univariate and multivariate survival analyses. We forced expression of PEDF in highly metastatic LoVo cells. The clonogenic survival assay was used to test the cellular sensitivity to radiation. Wound healing and Boyden chamber assays were used to detect cell migration and invasion. To assess the contribution of PEDF in vivo, we established tumor xenografts. The mechanisms of PEDF on cancer cells was analysed by bioinformatics. Our immunohistochemical staining of tissue samples revealed that prolonged DFS (77.1 vs $49.0 \%)$ and OS (87.1 vs 56.3\%) was observed in $\mathrm{PEDF}$-positive cases $(\mathrm{P}<0.001)$ following $n R T$. PEDF could be an independent factor for DFS [P=0.001; HR, 0.422 (95\% CI, 0.249-0.717)] and OS [P=0.003; HR, 0.418 (95\% CI, 0.234-0.749)]. Positive-expression of PEDF was negatively correlated with tumor differentiation $(\mathrm{P}<0.016)$, ypT stage $(\mathrm{P}<0.037)$, ypTNM stage $(\mathrm{P}<0.033)$, and ypN stage $(\mathrm{P}=0.006)$. Overexpression of PEDF in high metastatic cells enhanced radiosensitivity and, suppressed migration and invasion in vitro. In tumor xenografts, PEDF significantly suppressed tumor growth. Furthermore, by bioinformatics analysis, we
\end{abstract}

Correspondence to: Dr Jin Gu, Key Laboratory of Carcinogenesis and Translational Research (Ministry of Education), Department of Gastrointestinal Surgery III, Peking University Cancer Hospital and Institute, 52 Fucheng Rd., Haidian, Beijing 100142, P.R. China

E-mail: zlguj@bjmu.edu.cn

*Contributed equally

Key words: rectal carcinoma, pigment epithelium-derived factor, neoadjuvant radiotherapy, prognosis, radiosensitivity, metastasis found PEDF performs functions via activating P53 to regulate double-strand break repair pathway and activate the $G$ protein activation pathway. Our findings indicate that PEDF was identified as a predictive candidate for nRT responsiveness. These findings may be used to stratify LARC patients and make alternative strategies for adjuvant treatment.

\section{Introduction}

Locally advanced rectal carcinoma (LARC) is the third most common cancer and the third most common cancer cause of death globally (1). The prognosis of patients with LARC has slowly improved during the past decades in many countries (2), but there is much room to improve the treatment of patients suffering from colorectal cancer. At present, the standard procedures to treat LARC include neoadjuvant radiation therapy (nRT), surgery, and adjuvant therapy (3). Neoadjuvant therapy could further downstage tumors, improve the rate of sphincter preservation, and reduce the rate of local recurrence (4). For patients with stage II and III LARC, nRT reduces rates of local recurrence and toxic effects. Though rectal cancer patients have benefited from neoadjuvant therapy, the response of patients to neoadjuvant therapy varies from pathological complete response (pCR) (9-37\%) to complete resistance (5). Patients who achieved pCR have a prior prognosis compared with those who did not achieve pCR. The identification of patients at risk of being radioresistant would avoid the adverse side effects and cost of $\mathrm{nRT}$ and provide the patients alternative options such as surgical intervention without nRT (6). Even with nRT to achieve pCR, a substantial number of LARC patients will experience metastatic progression (7). Currently, it is inconclusive whether nRT may reduce the risk of metastatic development in rectal cancer (8). Therefore, identification of a specific molecular marker could be a target of neoadjuvant radiotherapeutic interventions. To date, however, no biomarker predicts tumor response to nRT and prevent metastatic progression.

Pigment epithelium-derived factor (PEDF; encoded by SERPINF1 and also known as EPC1), a serpin that has multiple biological actions, is a differentiation factor for retino- 
blastoma cells (9). PEDF is a potent inhibitor of angiogenesis (10). Many observations have shown that PEDF is implicated in several biological processes, such as neurogenesis, neuroprotection, anti-angiogenesis, retina protection, stem cell renewal, and inflammation (11). PEDF expresses in various kinds of cancers, such as lung cancer, pancreatic cancer, and breast cancer (12-14), and some research suggests that PEDF could be a new treatment to benefit cancer patients (15-17). In colorectal cancer (CRC), PEDF plays a role in inhibiting tumor growth and metastasis, anti-angiogenesis, decreasing tumor microvessel density (MVD) and tumor cell apoptosis, and recently, PEDF has also been identified as a prognostic marker for CRC (18-20). However, there are scarce data on the relationship between PEDF and sensitivity to nRT. This study evaluated the expression of PEDF after nRT and correlated the expression of PEDF with the clinicopathological parameters and prognosis of the disease.

\section{Materials and methods}

Subjects and samples. This research was approved by the ethics committee of the Health Science Center of Peking University and the Oncology Center at Peking University. Written informed consent was obtained from all the participants prior to the enrollment.

Pre-treatment biopsy tumor samples were obtained at colonoscopy or rigid sigmoidoscopy from 48 rectal cancer patients. To ensure consistent quality and tumor presence, both normal and tumor tissues were evaluated by an experienced pathologist.

We also retrospectively reviewed the data of 197 rectal cancer patients who received $30 \mathrm{~Gy} / 10$ fractions (10 f) nRT at Peking University Cancer Hospital between August 2003 and October 2009. Each subject conformed to the following inclusion criteria: i) diagnosis of rectal adenocarcinoma by biopsy; ii) resectable rectal cancer $\leq 10 \mathrm{~cm}$ from the anal verge; iii) evaluated by endorectal ultrasound (ERUS) or magnetic resonance imaging (MRI) before treatment; iv) presence of distant metastases excluded by imaging examinations; v) neoadjuvant radiotherapy of $30 \mathrm{~Gy} / 10 \mathrm{f}$; vi) radical surgery following total TME.

Patients with the following characteristics were excluded: i) cases with familial adenomatous polyposis LARC and hereditary non-polyposis colorectal carcinoma; ii) previous history (within 5 years) of malignant tumor; iii) presence of unresectable cancer; iv) death due to complications or other non-cancer related causes.

Tumor regression grade. The histology of all surgical specimens was reviewed and confirmed by an independent element and was classified based on the Mandard tumor regression grade (TRG) system (21), as follows: i) complete regression (fibrosis without detectable tissue of tumor); ii) fibrosis with scattered tumor cells; iii) fibrosis and tumor cells with preponderance of fibrosis; iv) fibrosis and tumor cells with preponderance of tumor cells; and v) tumor tissue lacking changes related to regression.

Tissue microarray and immunohistochemistry. Formalinfixed and paraffin-embedded specimens were microdissected to perform tissue microarrays (TMAs) with a tissue-arraying instrument (Beecher Instruments, Silver Spring, MD, USA). The TMAs were analyzed by immunohistochemistry as described previously (22). Sections were incubated with monoclonal antibodies against PEDF (1:100, Santa Cruz, Dallas, TX, USA). All images were examined by two experienced pathologists independently. PEDF immunohistochemical staining of a tissue sample was graded as either negative (patchy and weak or negative immunoreactivity) or positive (uniformly intense immunoreactivity) (Fig. 1).

Subcutaneous tumor xenografts. Ten NOD/SCID mice were randomly divided into LoVo-PEDF and LoVo-control groups $\left(n=5\right.$ per group). Equal amounts of corresponding cells $\left(2 \times 10^{6}\right)$ were subcutaneously implanted on the right buttock of each mouse. After three weeks, mice were sacrificed and xenografts were harvested and weighed. All animal experiments were reviewed and approved by the Ethics Review Committee at the Peking University School of Oncology.

Cell culture and cell lines. Human CRC cell lines (LoVo) from the American Type Culture Collection were cultured in DMEM medium with $10 \%$ fetal bovine serum (FBS) (Gibco, Grand Island, NY, USA) in a humidified atmosphere of $5 \% \mathrm{CO}_{2}$ at $37^{\circ} \mathrm{C}$. The cell lines have been tested and authenticated by STR profiling.

Animal. Female NOD-SCID mice (4-6-week-old) were provided by Beijing HFK Bio-technology Co., Ltd. (Beijing, China). Mice were maintained in a pathogen-free facility and used under the institutional guidelines for animal care.

Plasmid construction and cell transfection. PEDF-overexpressing cells were generated by using a ribozyme transgene system. Ribozyme transgenes specific for PEDF were synthesised and cloned into pEF6/V5-His TOPO TA expression plasmids in line with the manufacturer's protocol (Invitrogen, Shanghai, China). PEDF ribozyme transgene plasmids and control pEF6 plasmids were subsequently transfected into LoVo cells. Cells were placed in normal medium overnight to allow recovery and then in selection medium (normal medium containing blasticidin $5 \mu \mathrm{g} / \mathrm{ml}$ ) for eight days to select for cells containing the plasmid. Following selection, cells were placed into a maintenance medium $(0.5 \mu \mathrm{g} / \mathrm{ml}$ blasticidin $)$. Following selection, the cells were tested, at the translational level, for the efficacy of the expression plasmid.

Irradiation. Irradiation was delivered by linear accelerator at room temperature. The dose rate was $400 \mathrm{cGy} / \mathrm{min}$. The irradiation doses were 0,2 , and 4 Gy. After irradiation, the medium with drugs was adsorbed and replaced with fresh DMEM medium containing $10 \%$ FBS.

Growth curve. LoVo-TR and LoVo-PEDF Cells $\left(3 \times 10^{4}\right.$ cells/ well) were plated in a 96-well plate (Corning Life Science, MA, USA). After $24 \mathrm{~h}$, the medium was replaced. Growth curves were determined by placing cells in the IncuCyte ZOOM system (Essen BioScience), which allows an automated and non-invasive method of monitoring live cells in culture. A growth curve is constructed automatically from data points acquired during round-the-clock kinetic imaging. 


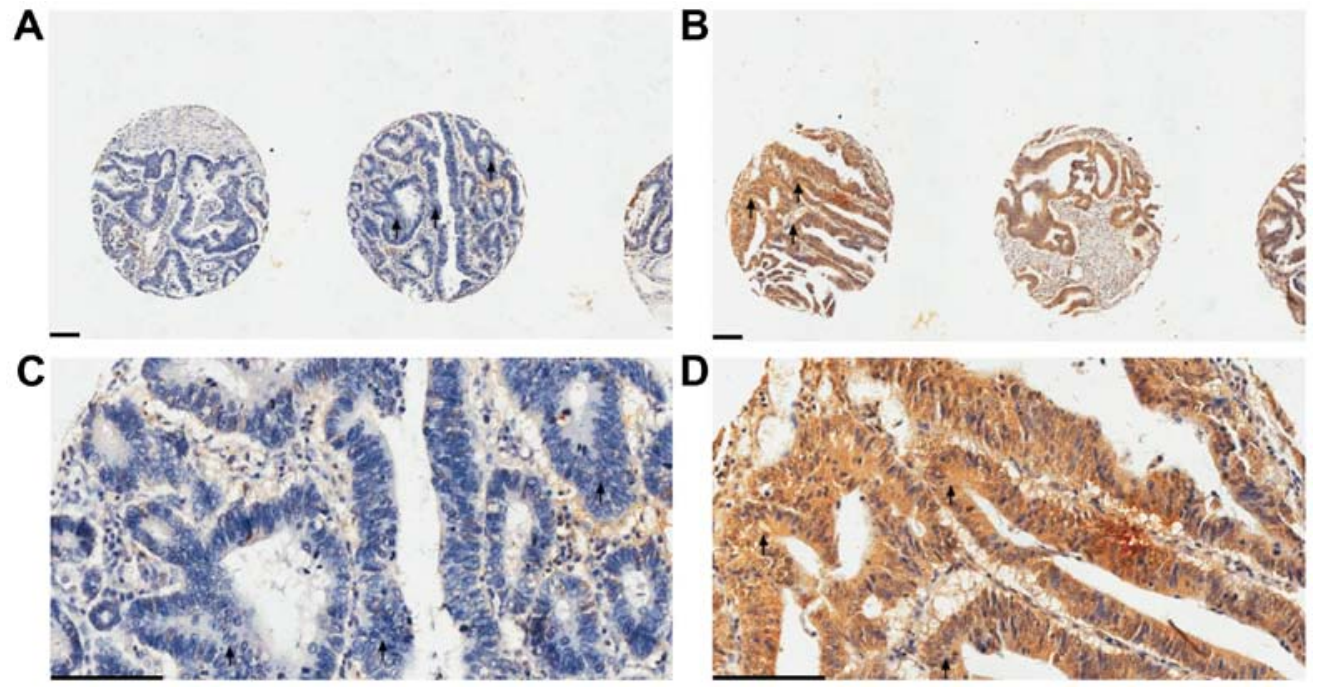

Figure 1. Representative immunohistochemical staining of serial sections of tissue microarrays for pigment epithelium-derived factor (PEDF). (A and B) The staining intensity of tumor tissues were graded as negative level (A) and positive level (B). (C and D) The carcinoma areas labeled by arrows in (A and B) were magnified 5 times as (C and D). Horizontal bar, $100 \mu \mathrm{m}$.

Clonogenic survival assay. The LoVo cells were plated at 200 cells per well in 6-well tissue culture plates and allowed to attach for $24 \mathrm{~h}$. The cells were incubated for $24 \mathrm{~h}$. Immediately after exposure of the cells to 0,2 , and $4 \mathrm{~Gy}$ of radiation, the medium was replaced with fresh DMEM supplemented with $10 \%$ FBS. Cells were incubated under standard growth conditions for 14 days, and the resultant colonies were stained with Giemsa. Colonies containing $\geq 50$ were scored manually.

Wound healing assay. Approximately $5 \times 10^{5}$ cells per well were seeded into 6-well culture plates and an incision was made in the central area of the confluent cells $24 \mathrm{~h}$ later. Cell migration near the wound area in confluent monolayers was monitored under a microscope (Leica, Germany) at the time of scratching, and after 24,48 , and $72 \mathrm{~h}$. The experiment was performed in triplicate with three independent repeats.

Transwell migration and invasion assay. To further evaluate the effect of PEDF on cell migration and invasion, $2.5 \times 10^{4}$ cells in $100 \mu \mathrm{l}$ DMEM with $1 \%$ FBS were plated into the upper chamber of the Transwell chamber $(8-\mu \mathrm{m}$ pore size; Corning Inc.). A total of $500 \mu \mathrm{l}$ of DMEM with $10 \% \mathrm{FBS}$ was loaded into the lower chamber to serve as a chemoattractant for the cells. After $24 \mathrm{~h}$, cells migrated to or invaded the other side of the membrane and were counted and imaged under a microscope (Leica), after fixing with $2 \%$ methanol and staining with $1 \%$ crystal violet solution. The experiments were repeated three times.

Protein extraction and western blotting. Cell proteins were extracted using RIPA buffer containing complete protease. Extracted protein $(20 \mu \mathrm{g})$ was separated by $10 \%$ SDS-PAGE and blotted onto PVDF membranes (Millipore, Billerica, MA, USA). Rabbit anti-PEDF (1:1,500 dilution; Abcam, Cambridge, MA, USA), mouse anti-P53 (1:2,000 dilution; Cell Signaling Technology), and mouse anti-GAPDH $(1: 10,000$ dilution; Bioworld Biotechnology, GA, USA) were used as primary antibodies. Horseradish-peroxidase-conjugated goat anti-rabbit or anti-mouse IgG (1:50,000 dilution, cwBiotech, Beijing, China) was used as secondary antibody. Signals were detected with a chemiluminescence (ECL) kit (Millipore).

TCGA datasets. One of the largest publicly available cancer datasets, the Cancer Genome Atlas (TCGA), was used to make the analysis (23). We downloaded the normalized gene expression data generated using the Illumina-GA RNA-seq platform data and Illumina-Hiseq RNA-seqV2 platform data and the DNA methylation data generated using Illumina Infinium Human Methylation 450 platform from the cBioPortal through the cgdsr $\mathrm{R}$ package (version 2.7.1). Gene expression values were transformed as $\mathrm{X}^{\prime}=\log 2 ð \mathrm{X}+1 \mathrm{P}$, where $\mathrm{X}$ represents the normalized fragments per kilobase transcript per million mapped reads values. Altogether, we collected 171 rectum adenocarcinoma patients for analysis from TCGA.

\section{Statistical analysis}

Association. Comparison of PEDF expression between the subgroups of various clinicopathological parameters was evaluated by $\chi^{2}$ test or Fisher's exact test. $\mathrm{P}<0.05$ was considered significant. Pearson correlation coefficient was used to estimate the strength and significance of the association between two continuous variables, such as gene expression and DNA methylation.

Prognosis. Categorical variables were analysed with Pearson's $\chi^{2}$ or Fisher's exact test, and the level of significance was set at 0.05 . The DFS was compared by the log-rank test using a Kaplan-Meier survival curve. Multivariate Cox proportional hazards regression was used to determine the independent factors affecting DFS, with the level of significance set at 0.05 .

Gene ontology/pathway analysis. To identify functional clusters of genes co-expressed with PEDF, we performed Functional Annotation Clustering using Reactome Pathway database (24) and SRTING online database (25). 
Table I. Association between clinicopathological features and pigment epithelium-derived factor status in the cohort received neoadjuvant radiotherapy.

\begin{tabular}{|c|c|c|c|}
\hline Variates & $\operatorname{PEDF}^{-}(\%)$ & $\mathrm{PEDF}^{+}(\%)$ & P-value \\
\hline Gender & & & 0.065 \\
\hline Male & $44(50.6)$ & $70(63.6)$ & \\
\hline Female & $43(49.4)$ & $40(36.4)$ & \\
\hline Age & & & 0.926 \\
\hline$<65$ & $63(72.4)$ & $79(71.8)$ & \\
\hline$>65$ & $24(27.6)$ & $31(28.2)$ & \\
\hline BMI & & & 0.734 \\
\hline$<19$ & $6 \quad(6.9)$ & $6 \quad(5.4)$ & \\
\hline $19-24$ & $45(54.7)$ & $63(57.3)$ & \\
\hline$>24$ & $36(41.4)$ & $41(37.3)$ & \\
\hline Surgery & & & 0.67 \\
\hline APR & $26(29.9)$ & $36(32.7)$ & \\
\hline Non-APR & $61(70.1)$ & $74(67.3)$ & \\
\hline Differentiation & & & 0.016 \\
\hline ypCR & $5 \quad(5.7)$ & $0 \quad(0.0)$ & \\
\hline G1-2 & $49(56.3)$ & $84(76.4)$ & \\
\hline G3-4 & $33(37.9)$ & $26(23.6)$ & \\
\hline TRG & & & 0.064 \\
\hline ypCR & $8 \quad(9.4)$ & $10(9.3)$ & \\
\hline Near ypCR & $57(67.1)$ & $83(76.9)$ & \\
\hline Minor regression & $20(27.5)$ & $15(13.9)$ & \\
\hline ypT & & & 0.037 \\
\hline T0 & $4 \quad(6.4)$ & $0 \quad(3.3)$ & \\
\hline $\mathrm{T} 1-2$ & $22(22.3)$ & $43(46.2)$ & \\
\hline T3-4 & $61(71.3)$ & $67(50.5)$ & \\
\hline ypN & & & 0.006 \\
\hline No & $39(44.8)$ & $60(64.5)$ & \\
\hline $\mathrm{N} 1-2$ & $33(37.9)$ & $31(34.5)$ & \\
\hline N3 & $15(17.2)$ & $1(1.0)$ & \\
\hline ypTNM stage & & & 0.033 \\
\hline I & $21(24.1)$ & $36(32.7)$ & \\
\hline II & $19(21.8)$ & $25(31.8)$ & \\
\hline III & $47(54.0)$ & $39(35.5)$ & \\
\hline LVI & & & 0.068 \\
\hline Negative & $16(18.4)$ & 10 & \\
\hline Positive & $71(81.6)$ & $100(90.9)$ & \\
\hline
\end{tabular}

BMI, body mass index; LVI, lymph vessel invasion; PEDF, pigment epithelium-derived factor; TRG, tumor regression grade.

Gene set enrichment analysis. To identify the pathways that are significantly enriched in genes associated with the PEDF, we computed the association of gene sets with PEDF calls using the following logistic regression model: $C=\beta 0+\beta 1 X$ described before (26).

\section{Results}

The association between PEDF expression level and clinicopathological features in LARC patients. To determine the relationship between the expression level of PEDF and clinical pathological variables, we examined PEDF expression by immunohistology in 197 human LARC tissues received nRT. As shown in Table I, the number of positively and negatively stained PEDF was counted. Consequently, we found 110 patients had positive PEDF expression. On analysis, low expression of PEDF was significantly correlated with tumor differentiation $(\mathrm{P}<0.016)$, ypT stage $(\mathrm{P}<0.037)$, and ypTNM stage $(\mathrm{P}<0.033)$. Of note, the PEDF expression level was significantly negatively correlated with ypN stage $(\mathrm{P}=0.006)$. Clinicopathological characteristics of all patients are summarized in Table I.

Positive PEDF expression is associated with prior disease-free survival and overall survival of LARC patients with nRT. For tumor specimens, Kaplan-Meier curve analysis revealed that positive expression of PEDF predicted prior patient diseasefree survival (DFS) and over survival (OS). Fig. 2A and B showed that the DFS time (77.1 vs $49.0 \%, \mathrm{P}<0.001)$ and OS time (87.1 vs $56.3 \%, \mathrm{P}<0.001$ ) for patients with positive PEDF expression were significantly longer than those for patients with negative PEDF expression. According to a univariate analysis (Table II), several clinicopathological parameters, including ypN stage, ypTNM stage, and PEDF, were important prognosistic factors for both DFS and OS. Cox proportional hazard regression analysis showed only PEDF, was significant, as an independent factor for DFS $[\mathrm{P}=0.001 ; \mathrm{HR}, 0.422$ (95\% CI, 0.249-0.717)] and OS [P=0.003; HR, 0.418 (95\% CI, 0.234-0.749)] (Table III). These data indicated that positive PEDF expression predicted prior prognosis for LARC patients received nRT.

PEDF may predict the radiosensitivity and prognosis for $L A R C$ patients. To determine the relationship between the expression level of PEDF and radiosensitivity, we examined PEDF expression by immunohistology in 48 pre-treatment biopsy tissues (Table IV). We found a trend that PEDF had a negative correlation with TRG, suggesting its role in sensitivity to nRT (correlation coefficient $=-0.290, \mathrm{P}=0.046$ ) (Table V). The same as TRG, positive PEDF expressing patients had a prior DFS time (81.3 vs $50.0 \%, \mathrm{P}=0.061)$ than those with negative PEDF expressing (Fig. 2C and D). However, we did not find the correlation between clinicopathological characteristics and PEDF status. All these data indicate that PEDF may be a factor to predict the radiosensitivity and prognosis for LARC patients.

PEDF suppresses LoVo cell proliferation, spread, migration, and invasion and enhances the radiation sensitivity. The relationship between increased expression of PEDF and cell invasion of LARC drove us to explore the possible biological functions of PEDF in cancer cells; therefore, we overexpressed PEDF in the highly metastatic LoVo cells. As shown in Fig. 3A, the expression of PEDF increased markedly in LoVo-PEDF cells (Fig. 3A). The survival rate and cell growth curve (Fig. 3B) showed PEDF played an important role in inhibiting cell proliferation. Clonogenic survival assay showed PEDF displayed a radiation-enhancing effect at the irradiation doses of 2 and 4 Gy in LoVo cells (Fig. 3C and D). LoVo cells that overexpressed PEDF showed a significant decrease in cell spreading (Fig. 3F), cell migration, and 

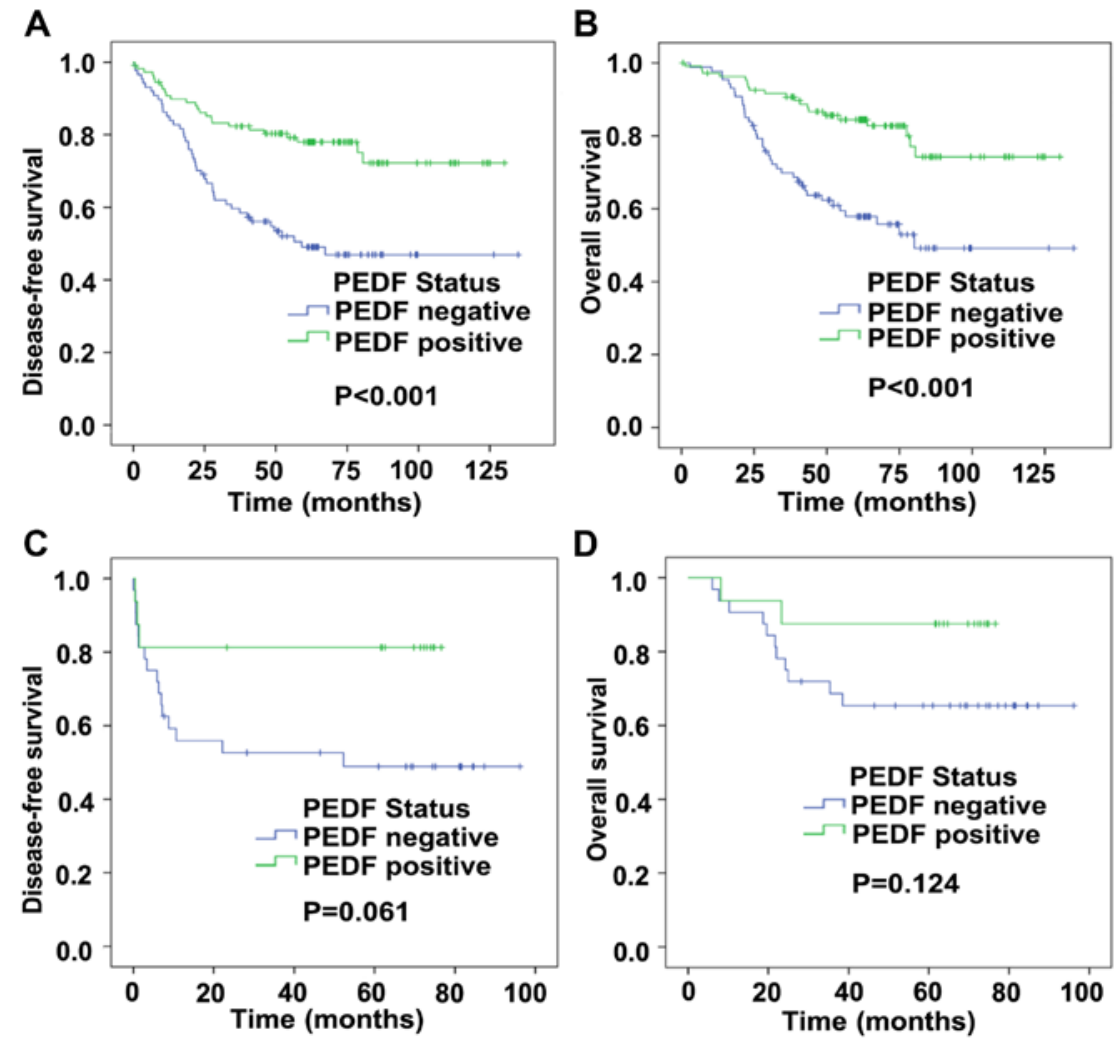

Figure 2. Pigment epithelium-derived factor (PEDF) status in tumor tissues is associated with prognosis. (A and B) In the cohort of post-treatment tumor tissues, disease-free survival (DFS) and overall survival (OS) for rectal cancer patients. (C and D) In the cohort of pre-treatment biopsy tissues, DFS and OS for rectal cancer patients.

Table II. Univariate log-rank analysis for important clinicopathological features and pigment epithelium-derived factor status in the cohort received neoadjuvant radiotherapy.

\begin{tabular}{lccccccr}
\hline & \multicolumn{3}{c}{ DFS } & & \multicolumn{2}{c}{ OS } \\
\cline { 2 - 3 } Parameter & HR & $95 \%$ CI & P-value & & HR & 95\% CI & P-value \\
\hline Gender & 0.867 & $0.579-1.459$ & 0.532 & & 0.846 & $0.497-1.438$ & 0.536 \\
Age & 1.126 & $0.674-1.881$ & 0.650 & & 1.299 & $0.751-2.248$ & 0.350 \\
BMI & 1.226 & $0.839-1.889$ & 0.266 & 1.379 & $0.879-2.162$ & 0.162 \\
Surgery & 1.575 & $0.971-2.557$ & 0.066 & & 1.734 & $1.023-2.940$ & 0.041 \\
Differentiation & 0.968 & $0.479-1.965$ & 0.928 & & 0.868 & $0.429-1.758$ & 0.695 \\
TRG & 0.927 & $0.714-1.205$ & 0.571 & & 0.799 & $0.491-1.301$ & 0.366 \\
ypT & 1.208 & $0.450-3.243$ & 0.708 & & 1.789 & $1.359-2.356$ & 0.000 \\
ypN & 1.599 & $1.252-2.041$ & 0.001 & & 2.926 & $1.816-4.713$ & 0.000 \\
ypTNM & 1.775 & $1.277-2.412$ & 0.000 & & 1.918 & $1.340-2.745$ & 0.000 \\
LVI & 0.577 & $0.365-1.086$ & 0.046 & & 0.621 & $0.336-1.148$ & 0.129 \\
PEDF & 0.381 & $0.233-0.623$ & 0.000 & & 0.351 & $0.204-0.604$ & 0.000 \\
\hline
\end{tabular}

BMI, body mass index; LVI, lymph vessel invasion; DFS, disease-free survival; OS, overall survival; PEDF, pigment epithelium-derived factor; TRG, tumor regression grade.

invasion (Fig. 3E), compared with control cells. In vivo, we confirmed PEDF decreased the ability of LoVo cells to form and grow tumors (Fig. 3G and $\mathrm{H}$ ). Collectively, overexpression of PEDF suppresses cell proliferation, spreading, migration, and invasion and enhances the radiation effect.
PEDF regulates the double-strand breaks (DSBs) repair pathway and activates $G$ protein pathway. Until now, the exact pathways that PEDF may regulate in LARC remain unclear. To probe the PEDF-associated pathways on an unbiased basis, we performed GSEA using the Illumina-GA RNA-seq platform 
Table III. Multivariate analysis for important cliniopathological features and pigment epithelium-derived factor status in the cohort received neoadjuvant radiotherapy.

\begin{tabular}{|c|c|c|c|c|c|c|}
\hline \multirow[b]{2}{*}{ Parameter } & \multicolumn{3}{|c|}{ DFS } & \multicolumn{3}{|c|}{ OS } \\
\hline & HR & $95 \% \mathrm{CI}$ & P-value & HR & $95 \% \mathrm{CI}$ & P-value \\
\hline Gender & 0.753 & $0.438-1.293$ & 0.303 & 0.744 & $0.409-1.355$ & 0.334 \\
\hline Age & 1.27 & $0.729-2.214$ & 0.399 & 1.567 & $0.861-2.851$ & 0.141 \\
\hline BMI & 1.163 & $0.742-1.832$ & 0.509 & 1.285 & $0.781-2.115$ & 0.323 \\
\hline Surgery & 1.488 & $0.882-2.509$ & 0.137 & 1.716 & $0.971-3.033$ & 0.063 \\
\hline Differentiation & 0.968 & $0.479-1.965$ & 0.46 & 0.654 & $0.256-1.670$ & 0.375 \\
\hline TRG & 0.912 & $0.529-1.751$ & 0.739 & 0.882 & $0.491-1.301$ & 0.684 \\
\hline ypT & 1.472 & $0.420-5.156$ & 0.545 & 1.319 & $0.373-4.668$ & 0.668 \\
\hline $\mathrm{ypN}$ & 1.355 & $0.705-2.605$ & 0.362 & 1.808 & $0.828-3.950$ & 0.137 \\
\hline ypTNM & 1.136 & $0.495-2.610$ & 0.763 & 0.9 & $0.341-2.372$ & 0.831 \\
\hline LVI & 0.851 & $0.365-1.086$ & 0.61 & 0.848 & $0.427-1.686$ & 0.639 \\
\hline PEDF & 0.422 & $0.249-0.717$ & 0.001 & 0.418 & $0.234-0.749$ & 0.003 \\
\hline
\end{tabular}

BMI, body mass index; LVI, lymph vessel invasion; DFS, disease-free survival; OS, overall survival; PEDF, pigment epithelium-derived factor; TRG, tumor regression grade.

Table IV. Association between clinicopathological features and PEDF status in the pre-treatment biopsy specimens.

\begin{tabular}{|c|c|c|c|}
\hline Variates & $\mathrm{PEDF}^{-}(\%)$ & $\operatorname{PEDF}^{+}(\%)$ & P-value \\
\hline Gender & & & 0.112 \\
\hline Male & $23(71.9)$ & $7(43.8)$ & \\
\hline Female & $9(28.1)$ & $9(56.2)$ & \\
\hline Age & & & 0.697 \\
\hline$<65$ & $25(78.1)$ & $14(87.5)$ & \\
\hline$>65$ & 7 (21.9) & $2(12.5)$ & \\
\hline Surgery & & & 0.750 \\
\hline APR & $22(68.8)$ & $10(62.5)$ & \\
\hline Non-APR & $10(31.3)$ & $6(37.5)$ & \\
\hline Differentiation & & & 0.329 \\
\hline ypCR & $4(12.5)$ & $\begin{array}{ll}0 & (0.0)\end{array}$ & \\
\hline G1-2 & $26(81.3)$ & $15(93.8)$ & \\
\hline G3-4 & $2(6.3)$ & $1(6.3)$ & \\
\hline $\mathrm{TRG}^{\mathrm{a}}$ & & & 0.146 \\
\hline ypCR & $1 \quad(4.5)$ & $2(18.2)$ & \\
\hline Near ypCR & $3(13.6)$ & $3(27.3)$ & \\
\hline Minor regression & $18(81.8)$ & $6(54.5)$ & \\
\hline ypT & & & 1.000 \\
\hline T0 & $3(9.4)$ & $0 \quad(0.0)$ & \\
\hline $\mathrm{T} 1-2$ & $6(18.8)$ & $5(31.3)$ & \\
\hline $\mathrm{T} 3-4$ & $23(71.9)$ & $11(68.8)$ & \\
\hline ypN & & & 0.841 \\
\hline No & $16(50.0)$ & $9(56.3)$ & \\
\hline N1-2 & $9(21.9)$ & $3(18.8)$ & \\
\hline N3 & $7(17.2)$ & $4(25.0)$ & \\
\hline ypTNM stage & & & 0.802 \\
\hline I & $8(25.0)$ & $4(25.0)$ & \\
\hline II & $8(25.0)$ & $5(31.3)$ & \\
\hline III & $16(50.0)$ & $7(43.8)$ & \\
\hline LVI & & & 0.652 \\
\hline Negative & $28(87.5)$ & $15(93.8)$ & \\
\hline Positive & $4(12.5)$ & $1(6.2)$ & \\
\hline
\end{tabular}

LVI, lymph vessel invasion; PEDF, pigment epithelium-derived factor; TRG, tumor regression grade. ${ }^{\mathrm{a}}$ TRG assessment was unavailable in 15 cases.
Table V. Spearman correlation test between tumor regression grade and PEDF status in the pre-treatment biopsy specimens.

\begin{tabular}{lrcc}
\hline Variates & PEDF $^{-}(\%)$ & PEDF $^{+}(\%)$ & P-value $^{\mathrm{a}}$ \\
\hline TRG & & & 0.046 \\
ypCR & $1(4.5)$ & $2(18.2)$ & \\
Near ypCR & $3(13.6)$ & $3(27.3)$ & \\
Minor regression & $18(81.8)$ & $6(54.5)$ & \\
\hline
\end{tabular}

PEDF, pigment epithelium-derived factor; TRG, tumor regression grade. ${ }^{\text {TThe }} \mathrm{P}$-value resulted from one-tailed test.

data of the rectal cancer cohort of The Cancer Genomic Atlas project (TCGA, 171 patients), GSEA is designed to detect coordinated differences in expression of predefined sets of functionally related genes (26). Among all the 674 predefined 'Reactome' gene sets, the DSBs repair pathway and G protein activation pathways were identified with a strongly negative and positive association, respectively, with PEDF expression in the TCGA rectal carcinoma dataset (Fig. 4A and B). By the analysis of LARC cohort of TCGA, parts of key genes correlated with the DSBs repair pathway (Fig. 4C) on mRNA levels were found to be negatively associated with PEDF (Fig. 5A). For genes correlated with the $\mathrm{G}$ protein activation pathway (Fig. 4D), parts of key genes were found to have positive association with PEDF (Fig. 5B). These findings consistently suggest that PEDF may be involved in the regulation of the DSBs repair pathway and enhancement of $G$ protein activation pathway.

PEDF activates $P 53$ to perform functions. To validate how PEDF is involved in the DSBs repair and G protein activation pathways, the online database STRING (25) was used to investigate interactions between PEDF and associated genes. By protein interaction analysis, we found P53 could be the downstream target gene of PEDF, and interaction network was 

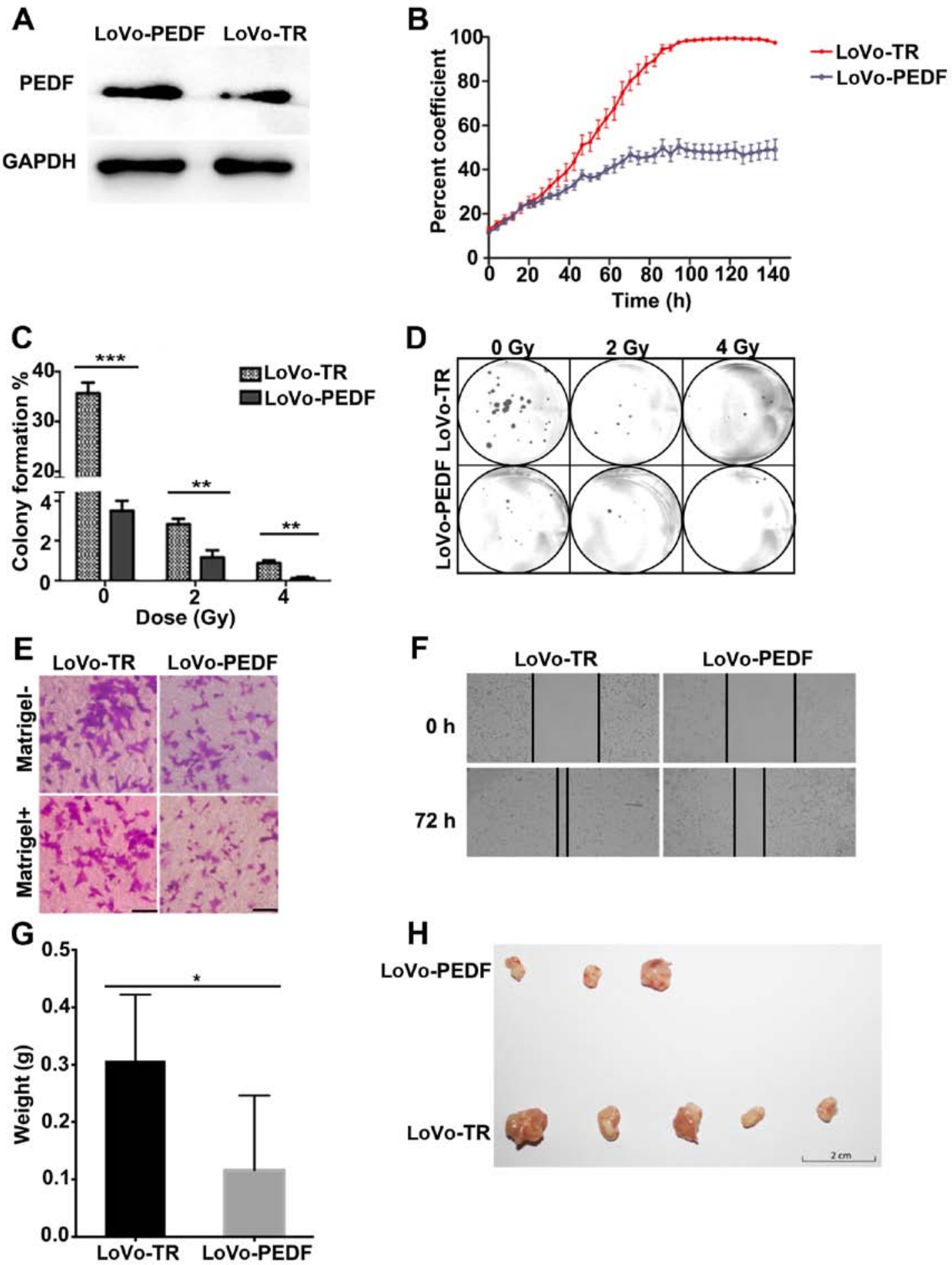

Figure 3. Overexpression of pigment epithelium-derived factor (PEDF) supresses LoVo cell proliferation, spread, migration and invasion and increases the radiosensitivity. (A) Western blotting using anti-PEDF antibody shows stable upregulation of PEDF in LoVo cells. (B) Growth rate was determined by the Incucyte real-time video imaging system. (C and D) Colonies and colony formation rates. Cells stably expressing PEDF were seeded on 6-well plates and examined by Giemsa staining 14 days after exposure to ionizing radiation. Data represented mean \pm SD of independent experiments run in triplicate. (E) Overexpression of PEDF decreased cell migration and invasion via Boyden chamber assay without and with Matrigel. Horizontal bar, $50 \mu \mathrm{m}$. (F) PEDF supressed spreading of LoVo cells in a wound healing assay. $(\mathrm{G})$ Tumors were removed and weighed four weeks after LoVo cells were injected under the skin. (H) Image of dissected tumors from mice injected with LoVo cells. P-values are ${ }^{*} \mathrm{P}<0.05,{ }^{* *} \mathrm{P}<0.01$ and ${ }^{* * *} \mathrm{P}<0.001$.

constructed (Fig. 5A). We then used The Cancer Cell Line Encyclopedia database (27) to confirm that P53 is wild-type in LoVo cells and has anticancer function (data not shown). We further validated that P53 was more highly expressed in LoVo cells with PEDF overexpression compared with the control cells (Fig. 5B). These findings consistently suggest that P53 is a downstream gene of PEDF.

PEDF expression is controlled by promoter methylation. The relationship between PEDF expression level and PEDF 

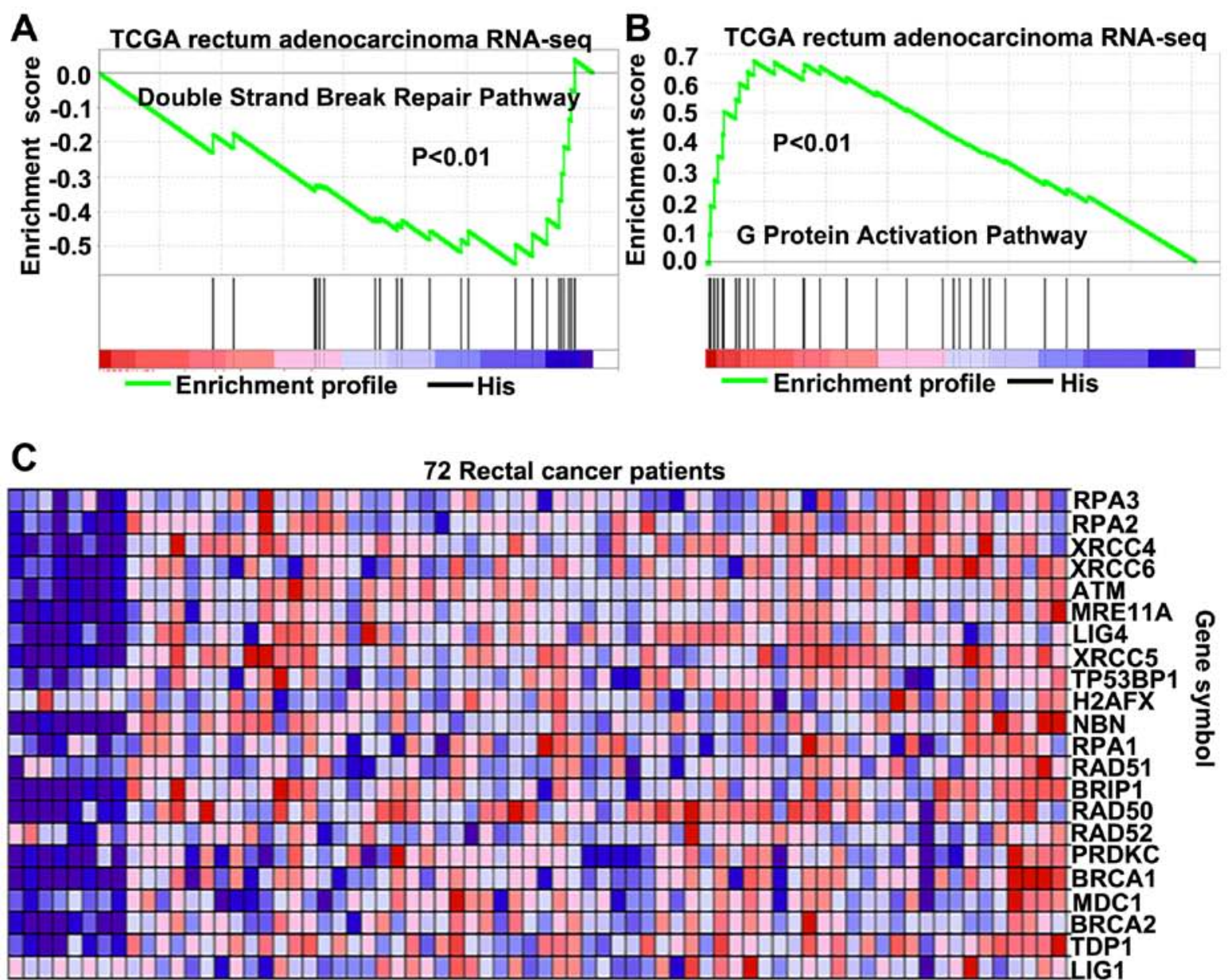

Double strand break repair gene set

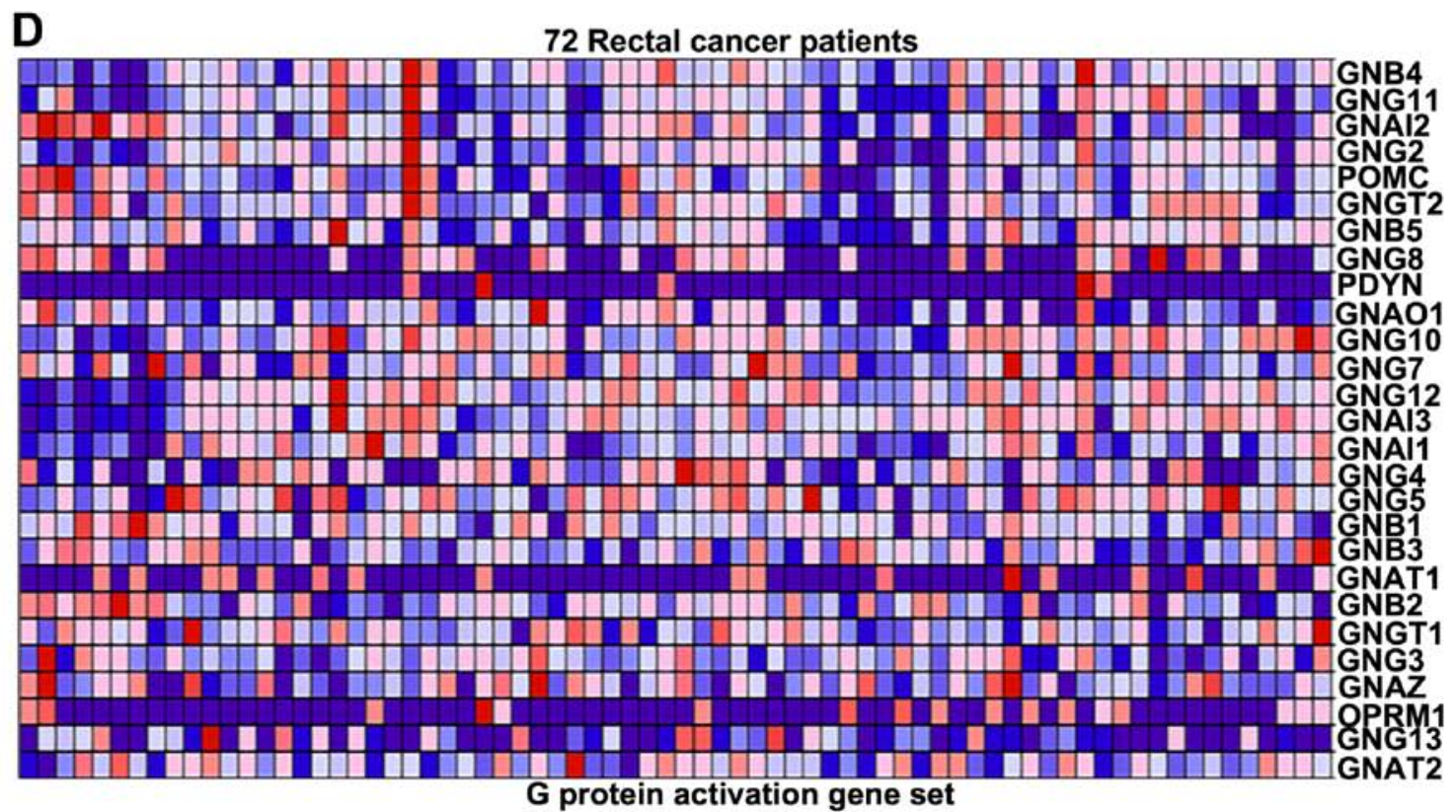

Figure 4. Pigment epithelium-derived factor (PEDF) regulates double-strand breaks (DSBs) repair pathway and activates G protein pathway. (A and B) Gene set enrichment analysis (GSEA) identified significant association between PEDF and DSBs repair pathway and G protein activation pathway in the TCGA colorectal cancer dataset. (C and D) The expression level of DSBs repair gene set and G protein activation gene set in 72 colorectal cancer patients.

promoter methylation status was analyzed using IlluminaHiseq RNA-seqV2 platform data and Illumina Infinium Human DNA Methylation 450 beadchip data.
To investigate whether PEDF methylation status affects the mRNA level in rectal cancer, we used the TCGA datebase (23) to make the correlation between methylation of 
A Correlation between

PEDF and BRCA1

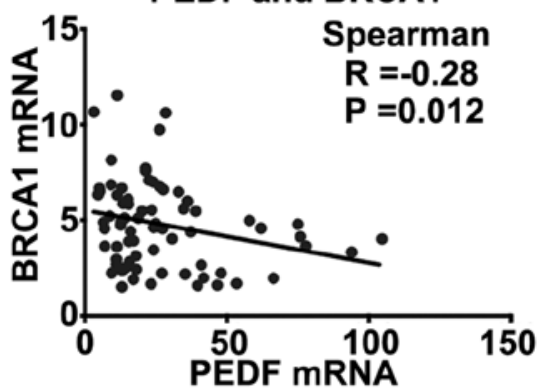

Correlation between

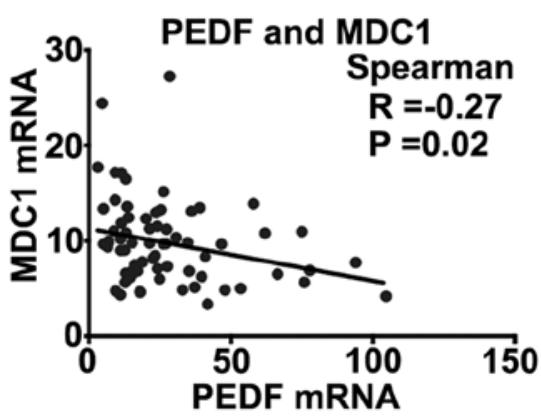

B

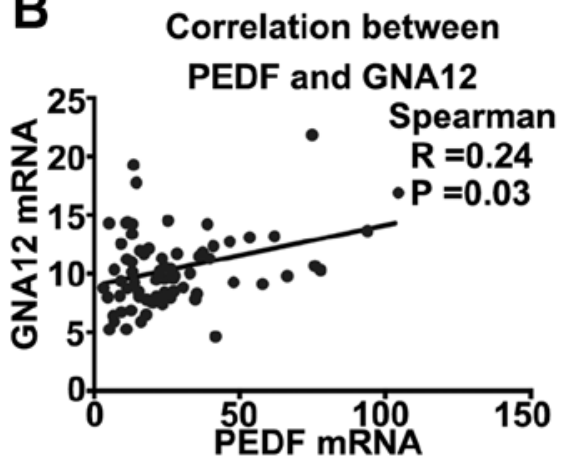

Correlation between

PEDF and GNGT2

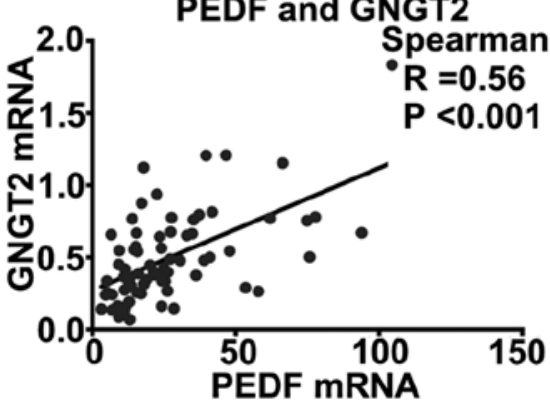

Correlation between

PEDF and BRCA2

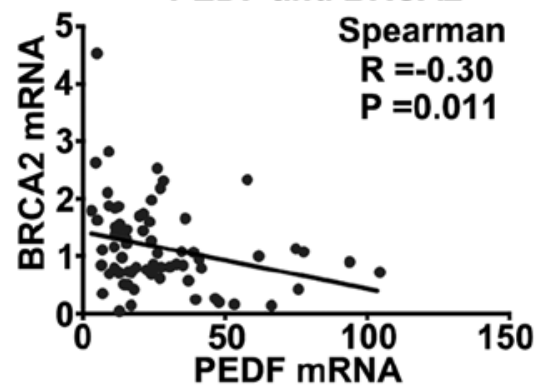

Correlation between

PEDF and RAD52

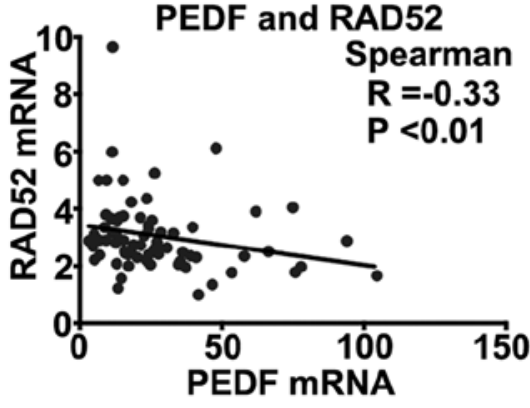

Correlation between

PEDF and GNAO1

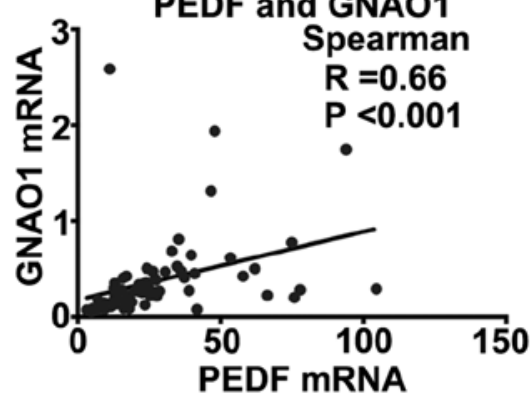

Correlation between

PEDF and GNG2

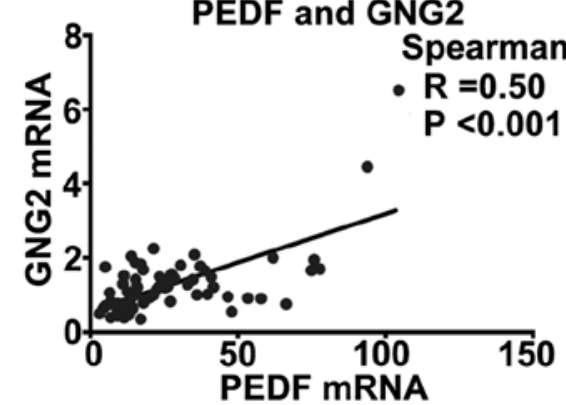

Correlation between

PEDF and LIG1
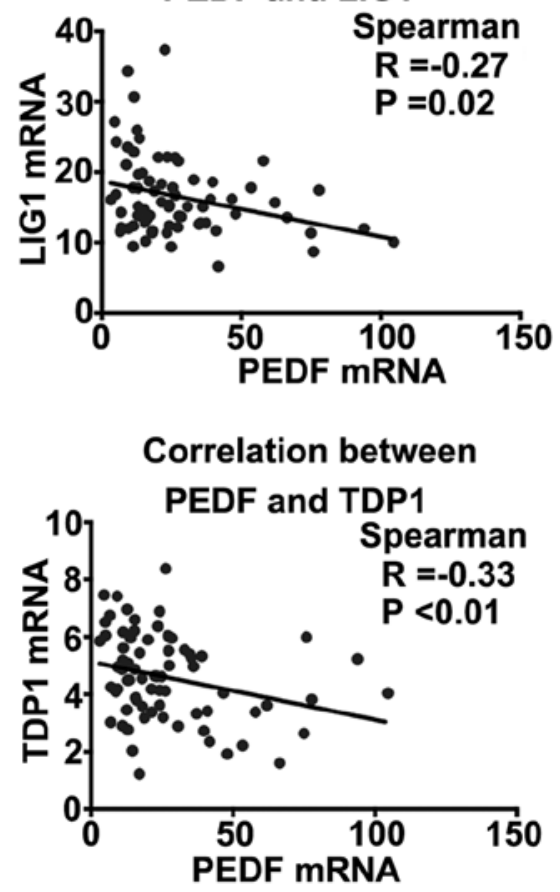

Figure 5. The key genes in double-strand breaks (DSBs) repair and G protein activation gene sets have a significant correlation with pigment epitheliumderived factor (PEDF). (A) The key genes in DSBs repair set negatively correlated with PEDF. (B) The key genes in G protein activation gene set positively correlated with PEDF.

PEDF cg11692409 and PEDF cg27102649 and PEDF mRNA expression level. The data showed that methylation of the two genomic coordinates significantly negatively correlated with PEDF mRNA expression (correlation coefficient $=-0.38$, $\mathrm{P}<0.001$ and correlation coefficient $=-0.44, \mathrm{P}<0.001)$ (Fig. 6C). 


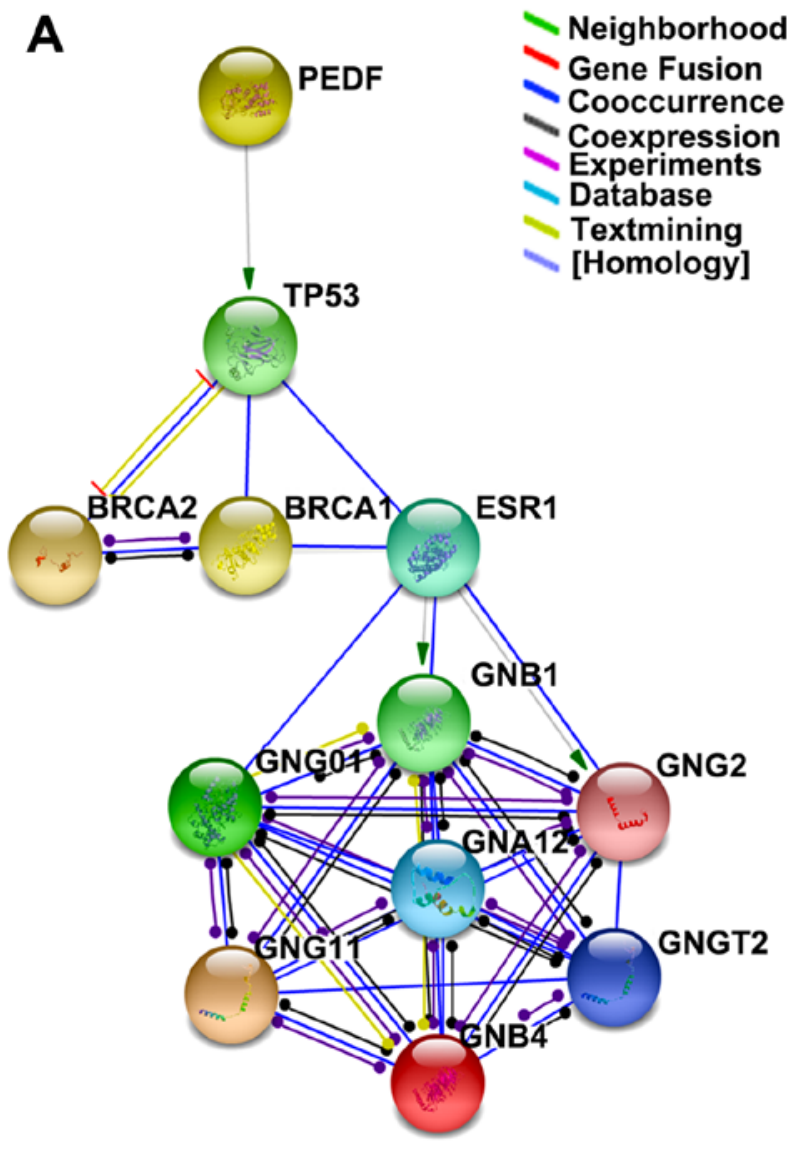

B LoVo-PEDF LoVo-TR

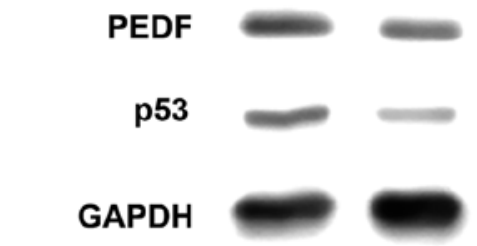

\section{Correlation between PEDF mRNA and DNA cg11692409 methylation level}

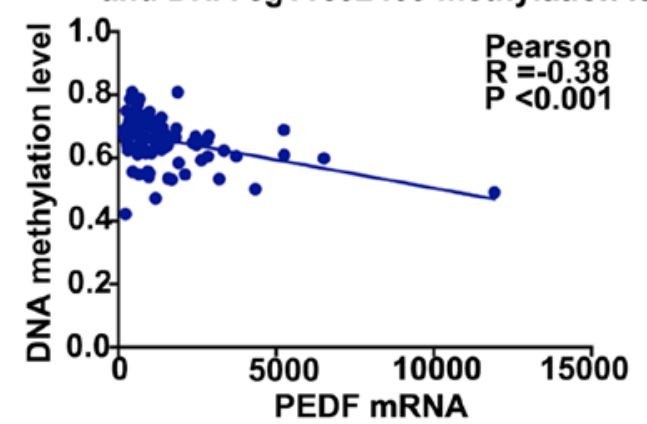

Correlation between PEDF mRNA and DNA cg27102649 methylation level

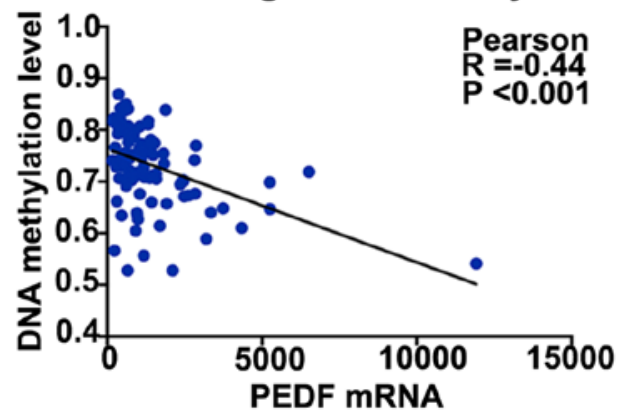

Figure 6. Pigment epithelium-derived factor (PEDF) activates P53 to perform functions and is regulated by DNA methylation level. (A) Schematic representation for PEDF regulatory pathway was made by STRING online database. (B) Western blotting showed P53 had a higher expression in PEDF overexpressed LoVo cells compared with the control cells. (C) The mRNA level of PEDF and DNA methylation level had a strong correlation in colorectal cancer tissues.

\section{Discussion}

PEDF has been found to enhance the antitumor effects of radiotherapy on nasopharyngeal carcinoma by downregulating VEGF expression and inhibiting angiogenesis (28), but the prognostic value of PEDF in response to nRT prognosis for LARC patients is rarely reported. To the best of our knowledge, this is the first time that PEDF expression was found to be different between the long-term DFS group and the short-term DFS group. LARC patients with high levels of PEDF had prior progression-free survial and tumor regression. The research demonstrated that PEDF could be a biomarker to predict the response of the LARC patients to $\mathrm{nRT}$; in vitro and in vivo data showed that PEDF could be a target for developing novel therapeutic strategies.

The nRT has become a standard treatment for LARC patients, and the nRT regimen we adopted in this study was $30 \mathrm{~Gy}$ in 10 fractions, which is recommended by the Chinese Anti-Cancer Association. Our previous data revealed prior response rates and clinical efficiency compared with traditional and published nRT regimens (29). However, not all patients are sensitive to it. Several studies have suggested TRG can be used to monitor treatment and as a prognostic parameter for patients who received nRT (30). The response to $\mathrm{nRT}$ varies from sensitivity to resistance, and some LARC patients suffer side effects and risk of disease progression during therapy (6). We found a new marker to predict the TRG before nRT, providing a new therapeutic strategy for LARC patients. In accordance with our data, PEDF contributed to radiosensitivity in melanoma therapy. Using quantitative reverse transcription PCR and immunohistochemical staining, we previously detected that low PEDF levels were associated with liver metastasis and disease-free survival in a large corhort of LARC patients (20).

In this study, we not only revealed that PEDF was an independent prognostic factor for DFS and OS in Cox regression analysis but also found that low expression of PEDF in LARC was associated with a high degree of ypN stage. Many researchers have found that lymph node metastases are significantly correlated with decreased survival in several solid tumors (31), and reduced PEDF levels in lung cancer tissues significantly correlated with lymph node metastasis (32). In 
addition to the anti-angiogenesis effect, PEDF plays a role in apoptosis, autophagy, and many other antitumor processes in various malignancies $(14,15)$. All of these suggest that PEDF may decrease lymph node metastasis in cancers.

Because of the association between PEDF and clinicopathological factors, we hypothesized that PEDF could increase the sensitivity of the tumor to nRT. DNA damage and hypoxia are important biological processes in chemoradiosensitivity $(33,34)$, and PEDF could induce cancer cell death by apoptosis and anti-angiogenesis during therapy (18-20). To confirm this hypothesis, we overexpressed PEDF in LoVo cells. Compared to the control, LoVo cells that overexpressed PEDF reduced tumorigenesis, with fewer colonies after exposure to the radiation. Metastasis and recurrence are the determining factors affecting DFS time of LARC patients, and angiogenesis has an indispensable implication on the invasive property of cancer cells (35-37). Simultaneous treatment with PEDF and radiation has an additive effect on the downregulation of VEGF expression and on angiogenesis inhibition (28). Therefore, our in vitro and in vivo results suggested that the higher level of PEDF expression promoted the DFS time by suppressing tumor growth and metastasis in LARC patients.

To further study the mechanism by which PEDF regulates the radiosensitivity and cell proliferation, we used the TCGA database to identify the PEDF-associated genes. The GSEA indicated that PEDF suppresses the DSBs repair pathway and activates the $G$ protein activation pathway and thus may provide useful information for targeted therapy. Demonstrating the effect of PEDF on regulating the pathways by STRING online database, we provide a more complete network that PEDF activates P53.

Gene expression is regulated by DNA methylation at $\mathrm{CpG}$ island promoter regions (38). Ha et al found that the methylation status of genes is associated with radiosensitivity to nRT (39). Our data demonstrated negative correlation between PEDF expression and its methylation status in LARC patients. The patients with low PEDF expression usually possess highlevel status of methylation, and our results indicate that the hypermethylation of PEDF could decrease its mRNA expression, generating angiogenesis and cancer cell proliferation, which induces tumor metastasis in LARC patients.

A number of limitations need to be noted regarding this study. The most important limitation lies in the fact that the limited pre-treatment sample size could not confirm the trend between the expression level of PEDF and TRG before $\mathrm{nRT}$, and we will accumulate more specimens to confirm the relationship. In addition, there is a variety of CRC cell lines available to us; we only used LoVo cells to identify the relationship between the level of PEDF expression and radiosensitivity signatures. The LoVo cell was used for overexpressed PEDF since it was exclusively lower expression compared to the other eight LARC cell lines. Researching ATCC, we determined that the LoVo cell line is derived from metastatic sites, which is suitable for our purpose. Next, we plan to validate the direct interaction between P53 and PEDF. Methylation status is different in CRC cell lines that are derived from diverse stages of CRC. Epigenetics signatures in LARC patients are also affected by various factors (38). Much more research is needed to prove the hypermethylation status of PEDF suppresses its mRNA transcription.
In concusion, that PEDF has a prognostic value to LARC patients after nRT. According to the level of PEDF expression, LARC patients may be stratified into risk subgroups and allow personalized therapeutic strategies. In addition to prolonging the DFS of patients, PEDF enhances the sensitivity of a tumor to nRT. Moreover, PEDF, as an anti-angiogenesis factor, possesses the potential to be an independent therapeutic agent for LARC patients.

\section{Acknowledgements}

This study was supported by the National Natural Science Foundation (81372593, 81201965), Beijing Natural Science Foundation (7132052), and the National High Technology Research and Development Program of China (863 Program) (no. 2012AA02A506, 2014AA020801). The authors would like to thank Dr Bin Dong, the Department of Pathology, Peking University Cancer Hospital and Institute for her technical assistance.

\section{References}

1. Siegel RL, Miller KD and Jemal A: Cancer statistics, 2015. CA Cancer J Clin 65: 5-29, 2015.

2. DeSantis CE, Lin CC, Mariotto AB, Siegel RL, Stein KD, Kramer JL, Alteri R, Robbins AS and Jemal A: Cancer treatment and survivorship statistics, 2014. CA Cancer J Clin 64: 252-271, 2014.

3. Brenner H, Kloor M and Pox CP: Colorectal cancer. Lancet 383: 1490-1502, 2014.

4. van Gijn W, Marijnen CA, Nagtegaal ID, Kranenbarg EM, Putter H, Wiggers T, Rutten HJ, Påhlman L, Glimelius B and van de Velde CJ; Dutch Colorectal Cancer Group: Preoperative radiotherapy combined with total mesorectal excision for resectable rectal cancer: 12-year follow-up of the multicentre, randomised controlled TME trial. Lancet Oncol 12: 575-582, 2011.

5. Huerta S, Gao X and Saha D: Mechanisms of resistance to ionizing radiation in rectal cancer. Expert Rev Mol Diagn 9: 469-480, 2009.

6. Huerta S, Hrom J, Gao X, Saha D, Anthony T, Reinhart H and Kapur P: Tissue microarray constructs to predict a response to chemoradiation in rectal cancer. Dig Liver Dis 42: 679-684, 2010.

7. Gérard JP, Azria D, Gourgou-Bourgade S, Martel-Lafay I, Hennequin C, Etienne PL, Vendrely V, François E, de La Roche G, Bouché O, et al: Clinical outcome of the ACCORD 12/0405 PRODIGE 2 randomized trial in rectal cancer. J Clin Oncol 30: 4558-4565, 2012.

8. Bosset JF, Calais G, Mineur L, Maingon P, Stojanovic-Rundic S, Bensadoun RJ, Bardet E, Beny A, Ollier JC, Bolla M, et al; EORTC Radiation Oncology Group: Fluorouracil-based adjuvant chemotherapy after preoperative chemoradiotherapy in rectal cancer: Long-term results of the EORTC 22921 randomised study. Lancet Oncol 15: 184-190, 2014.

9. Steele FR, Chader GJ, Johnson LV and Tombran-Tink J: Pigment epithelium-derived factor: Neurotrophic activity and identification as a member of the serine protease inhibitor gene family. Proc Natl Acad Sci USA 90: 1526-1530, 1993.

10. Dawson DW, Volpert OV, Gillis P, Crawford SE, Xu H, Benedict W and Bouck NP: Pigment epithelium-derived factor: A potent inhibitor of angiogenesis. Science 285: 245-248, 1999.

11. Becerra SP and Notario V: The effects of PEDF on cancer biology: Mechanisms of action and therapeutic potential. Nat Rev Cancer 13: 258-271, 2013.

12. Hong H, Zhou T, Fang S, Jia M, Xu Z, Dai Z, Li C, Li S, Li L, Zhang T, et al: Pigment epithelium-derived factor (PEDF) inhibits breast cancer metastasis by down-regulating fibronectin. Breast Cancer Res Treat 148: 61-72, 2014.

13. Guan M, Jiang H, Xu C, Xu R, Chen Z and Lu Y: Adenovirusmediated PEDF expression inhibits prostate cancer cell growth and results in augmented expression of PAI-2. Cancer Biol Ther 6: 419-425, 2007. 
14. Kim KJ, Yun JH, Heo JI, Lee EH, Min HS, Choi TH and Cho CH: Role of pigment epithelium-derived factor in the involution of hemangioma: Autocrine growth inhibition of hemangiomaderived endothelial cells. Biochem Biophys Res Commun 454: 282-288, 2014.

15. Ek ET, Dass CR and Choong PF: PEDF: A potential molecular therapeutic target with multiple anti-cancer activities. Trends Mol Med 12: 497-502, 2006.

16. Manalo KB, Choong PF and Dass CR: Pigment epitheliumderived factor as an impending therapeutic agent against vascular epithelial growth factor-driven tumor-angiogenesis. Mol Carcinog 50: 67-72, 2011.

17. Manalo KB, Choong PF, Becerra SP and Dass CR: Pigment epithelium-derived factor as an anticancer drug and new treatment methods following the discovery of its receptors: A patent perspective. Expert Opin Ther Pat 21: 121-130, 2011.

18. Wu QJ, Gong CY, Luo ST, Zhang DM, Zhang S, Shi HS, Lu L, Yan HX, He SS, Li DD, et al: AAV-mediated human PEDF inhibits tumor growth and metastasis in murine colorectal peritoneal carcinomatosis model. BMC Cancer 12: 129, 2012.

19. Cui FY, Song XR, Li ZY, Li SZ, Mu B, Mao YQ, Wei YQ and Yang L: The pigment epithelial-derived factor gene loaded in PLGA nanoparticles for therapy of colon carcinoma. Oncol Rep 24: 661-668, 2010

20. Ji D, Li M, Zhan T, Yao Y, Shen J, Tian H, Zhang Z and Gu J: Prognostic role of serum AZGP1, PEDF and PRDX2 in colorectal cancer patients. Carcinogenesis 34: 1265-1272, 2013.

21. Mandard AM, Dalibard F, Mandard JC, Marnay J, HenryAmar M, Petiot JF, Roussel A, Jacob JH, Segol P, Samama G, et al: Pathologic assessment of tumor regression after preoperative chemoradiotherapy of esophageal carcinoma. Clinicopathologic correlations. Cancer 73: 2680-2686, 1994.

22. Koumakpayi IH, Le Page C, Mes-Masson AM and Saad F. Hierarchical clustering of immunohistochemical analysis of the activated ErbB/PI3K/Akt/NF-kappaB signalling pathway and prognostic significance in prostate cancer. Br J Cancer 102: $1163-1173,2010$

23. Cancer Genome Atlas Network: Comprehensive molecular characterization of human colon and rectal cancer. Nature 487: 330-337, 2012

24. Croft D, Mundo AF, Haw R, Milacic M, Weiser J, Wu G, Caudy M, Garapati P, Gillespie M, Kamdar MR, et al: The Reactome pathway knowledgebase. Nucleic Acids Res 42D: D472-D477, 2014.

25. Szklarczyk D, Franceschini A, Wyder S, Forslund K, Heller D, Huerta-Cepas J, Simonovic M, Roth A, Santos A, Tsafou KP, et al: STRING v10: Protein-protein interaction networks, integrated over the tree of life. Nucleic Acids Res 43D: D447-D452, 2015.

26. Subramanian A, Tamayo P, Mootha VK, Mukherjee S, Ebert BL, Gillette MA, Paulovich A, Pomeroy SL, Golub TR, Lander ES, et al: Gene set enrichment analysis: A knowledge-based approach for interpreting genome-wide expression profiles. Proc Natl Acad Sci USA 102: 15545-15550, 2005.

27. Barretina J, Caponigro G, Stransky N, Venkatesan K, Margolin AA, Kim S, Wilson CJ, Lehár J, Kryukov GV, Sonkin D, et al: The Cancer Cell Line Encyclopedia enables predictive modelling of anticancer drug sensitivity. Nature 483 : 603-607, 2012.
28. Xu Z, Fang S, Zuo Y, Zhang Y, Cheng R, Wang Q, Yang Z, Cai W, Ma J, Yang X, et al: Combination of pigment epitheliumderived factor with radiotherapy enhances the antitumor effects on nasopharyngeal carcinoma by downregulating vascular endothelial growth factor expression and angiogenesis. Cancer Sci 102: 1789-1798, 2011.

29. Wang $\mathrm{L}$ and $\mathrm{Gu}$ J: Risk factors for symptomatic anastomotic leakage after low anterior resection for rectal cancer with $30 \mathrm{~Gy} / 10 \mathrm{f} / 2 \mathrm{w}$ preoperative radiotherapy. World J Surg 34: 1080-1085, 2010.

30. Stipa F, Chessin DB, Shia J, Paty PB, Weiser M, Temple LK, Minsky BD, Wong WD and Guillem JG: A pathologic complete response of rectal cancer to preoperative combined-modality therapy results in improved oncological outcome compared with those who achieve no downstaging on the basis of preoperative endorectal ultrasonography. Ann Surg Oncol 13: 1047-1053, 2006.

31. Meimarakis G, Angele MK, Schneider C, Weidenhagen R, Kalaitzis N, Molki A, Jauch KW, Hatz R and Winter H: Impact of systematic lymph node dissection in the resection of pulmonary metastases of solid extrapulmonary tumours. Zentralbl Chir 135: 556-563, 2010 (In German).

32. Chen J, Ye L, Zhang L and Jiang WG: The molecular impact of pigment epithelium-derived factor, PEDF, on lung cancer cells and the clinical significance. Int J Oncol 35: 159-166, 2009.

33. Yamaguchi $\mathrm{H}$, Bhalla $\mathrm{K}$ and Wang HG: Bax plays a pivotal role in thapsigargin-induced apoptosis of human colon cancer HCT116 cells by controlling Smac/Diablo and Omi/HtrA2 release from mitochondria. Cancer Res 63: 1483-1489, 2003.

34. Dewhirst MW, Cao Y and Moeller B: Cycling hypoxia and free radicals regulate angiogenesis and radiotherapy response. Nat Rev Cancer 8: 425-437, 2008.

35. Bhadada SV, Goyal BR and Patel MM: Angiogenic targets for potential disorders. Fundam Clin Pharmacol 25: 29-47, 2011.

36. Eefsen RL, Engelholm L, Willemoe GL, Van den Eynden GG, Laerum OD, Christensen IJ, Rolff HC, Høyer-Hansen G, Osterlind K, Vainer B, et al: Microvessel density and endothelial cell proliferation levels in colorectal liver metastases from patients given neo-adjuvant cytotoxic chemotherapy and bevacizumab. Int J Cancer 138: 1777-1784, 2016.

37. Yamada Y, Arao T, Matsumoto K, Gupta V, Tan W, Fedynyshyn J, Nakajima TE, Shimada Y, Hamaguchi T, Kato K, et al: Plasma concentrations of VCAM-1 and PAI-1: A predictive biomarker for post-operative recurrence in colorectal cancer. Cancer Sci 101: 1886-1890, 2010

38. Baylin SB and Ohm JE: Epigenetic gene silencing in cancer a mechanism for early oncogenic pathway addiction? Nat Rev Cancer 6: 107-116, 2006.

39. Ha YJ, Kim CW, Roh SA, Cho DH, Park JL, Kim SY, Kim JH, Choi EK, Kim YS and Kim JC: Epigenetic regulation of KLHL34 predictive of pathologic response to preoperative chemoradiation therapy in rectal cancer patients. Int J Radiat Oncol Biol Phys 91: 650-658, 2015 